\title{
Variation in hemolytic activity of Brachyspira hyodysenteriae strains from pigs
}

\author{
Maxime Mahu', Nele De Pauw', Lien Vande Maele ${ }^{1,2}$, Marc Verlinden ${ }^{1}$, Filip Boyen ${ }^{1}$, Richard Ducatelle , \\ Freddy Haesebrouck ${ }^{1}$, An Martel ${ }^{1}$ and Frank Pasmans ${ }^{1 *}$
}

\begin{abstract}
Brachyspira hyodysenteriae is the primary cause of swine dysentery, which is responsible for major economic losses to the pig industry worldwide. The hemolytic activity of 10 B. hyodysenteriae strains isolated from stools of pigs with mild to mucohemorrhagic diarrhea was compared and seven hemolysis associated genes were sequenced. Hemolysis induced by these strains varied from strong to near absent. One weakly hemolytic $B$. hyodysenteriae strain showed sequence changes in five hemolysis associated genes (tlyA, tlyB, hemolysin III, hemolysin activation protein and hemoIysin III channel protein) resulting in amino acid substitutions. The occurrence of weakly hemolytic strains identifiable as $B$. hyodysenteriae should be taken into account in swine dysentery diagnostics. The presence of these strains may affect herd dysentery status, with great impact on a farms trading opportunities.
\end{abstract}

\section{Introduction}

Swine dysentery (SD) is caused by the anaerobic spirochete Brachyspira hyodysenteriae and is an important intestinal disease in swine rearing countries. Clinical signs typically consist of mucohemorrhagic diarrhea. The economic losses on farm level can be substantial due to mortality, diminished growth rates, deterioration of feed conversion and costs of medical treatment [1]. The occurrence of $B$. hyodysenteriae in a herd may affect the trading of pigs with economic consequences, even in the absence of overt clinical signs. Diagnostics of herds for the presence of $B$. hyodysenteriae is usually done by examining pooled fecal samples for the presence of this micro-organism by microbial culture and/or PCR tests [2].

Besides B. hyodysenteriae, other Brachyspira species of varying virulence have been described in pigs. There has been an interest in putative virulence factors to help explain the differential pathogenic potential of these different Brachyspira spp. Possible virulence factors include motility, chemotactic capacities, lipopolysaccharide, hemolysin(s) and enzymes such as NADH oxidase $[1,3]$.

\footnotetext{
${ }^{*}$ Correspondence: frank.pasmans@ugent.be

${ }^{1}$ Department of Pathology, Bacteriology and Avian Diseases,

Faculty of Veterinary Medicine, Ghent University, Salisburylaan 133,

B-9820 Merelbeke, Belgium

Full list of author information is available at the end of the article
}

The pronounced hemolysis of $B$. hyodysenteriae that is displayed by growth on blood agar plates has been considered a hallmark of its pathogenicity $[4,5]$. Apart from $B$. pilosicoli, weakly hemolytic porcine Brachyspira spp. such as $B$. murdochii and $B$. intermedia are indeed regarded mildly or non-pathogenic. Although they have been isolated from clinical cases of diarrhea [6], their pathogenic potential is less clear-cut since experimental infections require large numbers of spirochetes and clinical symptoms are either mild or absent [7]. On the other hand, virulence of the recently described strongly hemolytic $B$. suanatina and "B. hampsonii" is considered to be similar to that of B. hyodysenteriae [8-13].

Several reports describe the purification of hemolysin produced by $B$. hyodysenteriae $[4,5,14]$. Using purified hemolysin in an ileal-colonic loop model, microscopic lesions similar to those seen in natural cases of swine dysentery have been reproduced [15]. Four hemolysis associated genes have been defined: $t l y A, t l y B, t l y C$ and hlyA [16-18]. The protein encoded by tlyA, hemolysin A, shows homology with pore forming hemolysins of several bacteria such as Mycobacterium tuberculosis [19, 20], and Treponema denticola [21]. These homologues and Hemolysin A also encompass a conserved domain which is predicted to function as a rRNA methyltransferase [21]. TlyA negative B. hyodysenteriae mutants are 
less hemolytic and induce less severe lesions in mice and pigs compared to their wildtype [22, 23]. The $T l y B$ gene encodes a Clp protease, and $t l y C$ encodes hemolysin C. Both recombinant proteins were proven to show hemolytic and cytotoxic activity in vitro [17]. Bellgard et al. [24] describe that, in order to display a hemolytic phenotype, $B$. hyodysenteriae could need an acyl carrier protein (ACP) for acylation of toxins. Such an ACP is encoded for by $h l y A$. The $f a b F$ and $f a b G$ genes encode an ACPreductase and synthase that presumably play a role in the lipidation of the HlyA protein [25]. Even though some weakly hemolytic Brachyspira spp. strains also contain the $h l y A$ gene, it is probably not functional due to incorrect localization between the $f a b$ genes [26].

In addition to previously described hemolysis related genes tlyA, tlyB, tlyC and hlyA-ACP Bellgard et al. [24] found three possibly important additional genes when the whole genome sequence of reference strain WA1 was described: hemolysin III, hemolysin activation protein and hemolysin III channel protein genes. Hemolysin III (BHWA1_RS02195) [24], encompasses a conserved domain yqfA, a predicted channel-forming protein of the hemolysin III family. Homologues of hemolysin III are found in several bacteria such as Bacillus cereus [27]. The hemolysin III related channel protein (BHWA1_ RS09085) [24], has a conserved domain composing an integral membrane protein. The hemolysin activation protein (BHWA1_RS02885) [24], shares conserved domains with hemolysin C.

We previously mentioned the existence of B. hyodysenteriae strains with an aberrant hemolytic phenotype [28]. In 1982, Lysons et al. [29] isolated three strains of $B$. hyodysenteriae that were reported to appear slightly less hemolytic on blood-containing agar plate than virulent strains of $B$. hyodysenteriae, though considerably more hemolytic than avirulent $B$. innocens. Disease signs could not be induced using two of these strains in an in vivo experiment, even when animals were colonized by the strain. Recently, Hampson et al. [30] described the existence of weakly hemolytic $B$. hyodysenteriae strains in Australia as well. The current study aims to quantify the hemolytic capacity of a selection of B. hyodysenteriae strains and to identify the underlying molecular differences.

\section{Materials and methods}

\section{Brachyspira isolate collection and selection}

A collection of isolates of different Brachyspira species was composed during a 6 month period (Oct 2011March 2012) at our facilities. B. hyodysenteriae isolates were collected by the participation of swine veterinarians who were asked to share fresh fecal samples, if $B$. hyodysenteriae infection was suspected on a farm based on clinical symptoms. Furthermore two diagnostic laboratories (Animal Healthcare Flanders, Drongen, Belgium and Mediclab, Aalst, Belgium) donated isolates of B. hyodysenteriae and other porcine associated Brachyspira species that they had collected during the past 2 years (2010-2011).

Participating swine veterinarians collected two or three pooled fecal samples (3 pigs per pooled sample) on each farm which were cultured within $24 \mathrm{~h}$ after sampling on selective plates consisting of Trypticase Soy Agar (TSA) (Sigma-Aldrich, St. Louis, MO, USA) supplemented with 5\% sheep blood (E\&O Laboratories, Bonnybridge, UK), $1 \%$ yeast extract (Becton-Dickinson, Franklin Lakes, NJ, USA), $25 \mu \mathrm{g} / \mathrm{mL}$ vancomycin, $400 \mu \mathrm{g} / \mathrm{mL}$ spectinomycin and $25 \mu \mathrm{g} / \mathrm{mL}$ colistin (all antimicrobial compounds from Sigma-Aldrich). Plates were anaerobically incubated at $38{ }^{\circ} \mathrm{C}$. Isolates were purified by three to five subcultures on Trypticase Soy Agar (TSA) plates supplemented with $5 \%$ sheep blood and $1 \%$ yeast extract [31] and eventually stored at $-70{ }^{\circ} \mathrm{C}$ in $300 \mu \mathrm{L}$ of a medium consisting of $75 \mathrm{~mL}$ horse serum (Thermo Fisher Scientific, Carlsbad CA, USA) and $25 \mathrm{~mL}$ Brain Heart Infusion broth (BioRad, Hercules CA, USA) supplemented with $10 \%$ (w/v) glucose (Merck, Darmstadt, Germany) until further use. Isolates donated by diagnostic laboratories were delivered on agar plates. All isolates were subcultured once after which they were also stored at $-70{ }^{\circ} \mathrm{C}$. All donated isolates were accompanied by a brief description of clinical symptoms on the farm of origin.

On all collected isolates phenotypic characterization and species-specific PCR's were performed. Phenotypic characterization was performed on pure 4-day old cultures and was based on beta-hemolysis, indole production, hippurate hydrolysis and the presence or absence of $\alpha$-galactosidase and $\beta$-glucosidase [32, 33]. Indole production was determined using a spot-indole test (Remel BactiDrop, Dartford, UK). For the other biochemical characteristics, commercial discs were used according to the manufacturer's instructions (Rosco Diatabs, Taastrup, Denmark). Type strains of B. hyodysenteriae (ATCC 27164), B. pilosicoli (ATCC 51139) and B. innocens (ATCC 29796) were included to provide positive controls for all the phenotypic characteristics that were examined.

Three B. hyodysenteriae-specific PCRs were performed, based on the following genes: tlyA [34], 23S rRNA [35] and nox [36]. Species-specific PCR for the other species were based on nox [37] and 23S rRNA [35] for B. intermedia, 16S rRNA [36] for B. pilosicoli and nox [38] for B.murdochii/B.innocens.

Out of the complete collection of $B$. hyodysenteriae isolates, 8 were selected at random to be evaluated in an in vitro assay for hemolytic capacity, MLST profiling, and sequence analysis of $16 \mathrm{~S}$ rRNA, the NADH oxidase 
gene, and hemolysis associated genes. Two more isolates were specifically selected for the same assays, since they showed an aberrant phenotype when grown on blood containing agar plates: M2 showed only moderate hemolysis and isolate D28 showed weak hemolysis. Strain B204 (ATCC 31212) was included as a positive control. These 10 selected isolates, the year of isolation, and the clinical symptoms on the farm of origin are given in Table 1. All isolates originated from different, non-related farms, except isolates M1 and M2, which originated from the same farm. M1 was isolated from fecal samples of finisher pigs, M2 was isolated from fecal samples of growing pigs. Both age groups suffered from mucohaemorrhagic diarrhea.

\section{Sequencing of 16S rRNA, NADH oxidase and Multi Locus Sequence Typing genes}

The NADH oxidase (nox) gene and 16S rRNA gene were partially sequenced as previously described $[39,40]$. The sequences retrieved from the isolates used in this study were compared by BLAST analysis to known sequences of B. hyodysenteriae type- and reference strains [41].

Multilocus sequence typing (MLST) of the B. hyodysenteriae isolates was based on the MLST scheme as previously published [42] and performed with modifications [43]. For all strains, sequences for genes encoding alcohol dehydrogenase ( $a d h)$, alkaline phosphatase $(a l p)$, esterase (est), glutamate dehydrogenase $(g d h)$, glucose kinase $(g l p K)$, phosphoglucomutase $(p g m)$ and thiolase (thi) were determined and matched with the online MLST database [44]. The concatenated sequences of the described isolates, a previously typed Belgian strain Be45 [45], reference strains B204 (ATCC 31212) and WA1 (ATCC 49526) and four B. intermedia strains were aligned using ClustalW. The $B$. intermedia strains included the type strain PWS/A (ATCC 51140), and three strains isolated from pigs previously described by Råsbäck et al. [42]. A dendrogram was constructed using Kimura distance calculation and unweighed pair group method with averages (UPGMA).

Table 1 Clinical signs on the farm of origin, phenotypic characteristics, MLST profile and sequence type, 16S rRNA and nox sequence lengths and accession numbers

\begin{tabular}{|c|c|c|c|c|c|c|c|}
\hline Strain ID & $\begin{array}{l}\text { Year of isola- } \\
\text { tion }\end{array}$ & $\begin{array}{l}\text { Clinical signs } \\
\text { on the farm } \\
\text { of origin }^{b}\end{array}$ & $\begin{array}{l}\text { Hemolysis } \\
\text { on agar plate }\end{array}$ & $\begin{array}{l}\text { Enzymatic } \\
\text { profile }^{d}\end{array}$ & $\begin{array}{l}\text { MLST profile } \\
\text { (sequence } \\
\text { type) }\end{array}$ & $\begin{array}{l}\text { Nox sequence } \\
\text { accession } \\
\text { number } \\
\text { and sequence } \\
\text { length (bp) }\end{array}$ & $\begin{array}{l}\text { 16S rRNA } \\
\text { sequence acces- } \\
\text { sion number } \\
\text { and sequence } \\
\text { length (bp) }\end{array}$ \\
\hline $3 b \| l l$ & 2011 & MH diarrhea & ++ & 1001 & $\begin{array}{l}\text { 2-11-3-1-10-2-21 } \\
\quad \text { (ST167) }\end{array}$ & $\begin{array}{l}\text { KM052166 } \\
990\end{array}$ & $\begin{array}{l}\text { KM112083 } \\
1286\end{array}$ \\
\hline $4 \mathrm{Cl}$ & 2011 & MH diarrhea & ++ & 1001 & $\begin{array}{l}\text { 2-11-3-1-10-2-21 } \\
\quad \text { (ST167) }\end{array}$ & $\begin{array}{l}\text { KM052167 } \\
975\end{array}$ & $\begin{array}{l}\text { KM112082 } \\
1286\end{array}$ \\
\hline $8 d l l$ & 2011 & MH diarrhea & ++ & 1001 & $\begin{array}{l}2-2-3-12-11-1-3 \\
\quad \text { (ST8) }\end{array}$ & $\begin{array}{l}\text { KM052168 } \\
1000\end{array}$ & $\begin{array}{l}\text { KM112081 } \\
1319\end{array}$ \\
\hline $10 c l$ & 2011 & mild diarrhea & ++ & 1001 & $\begin{array}{l}\text { 2-11-8-4-9-2-3 } \\
\quad \text { (ST168) }\end{array}$ & $\begin{array}{l}\text { KM052169 } \\
971\end{array}$ & $\begin{array}{l}\text { KM112080 } \\
1299\end{array}$ \\
\hline $21 b l$ & 2012 & MH diarrhea & ++ & 0001 & $\begin{array}{l}\text { 2-13-3-6-10-2-3 } \\
\quad \text { (ST169) }\end{array}$ & $\begin{array}{l}\text { KM052170 } \\
977\end{array}$ & $\begin{array}{l}\text { KM112079 } \\
1299\end{array}$ \\
\hline $25 \mathrm{cl}$ & 2012 & MH diarrhea & ++ & 1001 & $\begin{array}{l}\text { 2-18-8-5-6-1-11 } \\
\quad \text { (ST170) }\end{array}$ & $\begin{array}{l}\text { KM052171 } \\
1005\end{array}$ & $\begin{array}{l}\text { KM112078 } \\
1350\end{array}$ \\
\hline$M 1^{\mathrm{a}}$ & 2011 & MH diarrhea & ++ & 1001 & $\begin{array}{l}\text { 2-2-3-12-11-1-3 } \\
\quad \text { (ST8) }\end{array}$ & $\begin{array}{l}\text { KM052172 } \\
933\end{array}$ & $\begin{array}{l}\text { KM112077 } \\
1175\end{array}$ \\
\hline$M 2^{a}$ & 2011 & MH diarrhea & + & 1001 & $\begin{array}{l}2-2-3-12-11-1-3 \\
\quad \text { (ST8) }\end{array}$ & $\begin{array}{l}\text { KM052173 } \\
983\end{array}$ & $\begin{array}{l}\text { KM112076 } \\
1175\end{array}$ \\
\hline D1 & 2010 & MH diarrhea & ++ & 1001 & $\begin{array}{l}\text { 2-11-8-5-10-2-6 } \\
\quad \text { (ST171) }\end{array}$ & $\begin{array}{l}\text { KM052174 } \\
986\end{array}$ & $\begin{array}{l}\text { KM112075 } \\
1300\end{array}$ \\
\hline D28 & 2011 & mild diarrhea & \pm & 0001 & $\begin{array}{l}\text { 2-11-3-20-6-2-21 } \\
\quad \text { (ST172) }\end{array}$ & $\begin{array}{l}\text { KM052175 } \\
1005\end{array}$ & $\begin{array}{l}\text { KM112074 } \\
1182\end{array}$ \\
\hline $\begin{array}{l}\text { B204 (ATCC } \\
31212 \text { ) }\end{array}$ & - & MH diarrhea & ++ & 1001 & $\begin{array}{l}1-16-3-4-2-3-6 \\
\text { (ST54) }\end{array}$ & $\begin{array}{l}\text { U19610.1 } \\
1705\end{array}$ & $\begin{array}{l}\text { U14932.1 } \\
1433\end{array}$ \\
\hline \multicolumn{8}{|c|}{ Strains M1 and M2 were isolated on one farm, all other isolates originated from different, non-related farms. } \\
\hline \multicolumn{8}{|c|}{ b Clinical signs on the farm from which each strain was isolated, $\mathrm{MH}=$ mucohemorrhagic. } \\
\hline \multicolumn{8}{|c|}{$c++=$ strong,$+=$ moderate, $\pm=$ weak. } \\
\hline \multicolumn{8}{|c|}{ d indole production, hippurate hydrolysis, a-galactosidase, $\beta$-glucosidase (1 present, 0 absent). } \\
\hline e allele numb & radh-aln-est-adh & oK-pam-thi. Betwe & brackets sequence & vpe as acsiane & h MI ST datahase & & \\
\hline
\end{tabular}




\section{In vitro hemolysis assay}

The hemolysis assay was based on the assays described by Fedorka-Cray et al. [46] and ter Huurne et al. [17] with some modifications. Fresh blood was collected from 8 week old pigs and a volume of blood was immediately mixed with an equal volume of Alsever's solution (SigmaAldrich) $(50 / 50 \mathrm{v} / \mathrm{v})$. This blood-Alsever's mixture was washed three times with Dextrose-Glucose-Veronal (DGV) (Lonza, Walkersville, MD, USA) buffered solution by centrifugation for $10 \mathrm{~min}$ at $500 \mathrm{~g}$. The hematocrit of the suspension was determined using a micro-hematocrit centrifuge and reader. DGV buffered solution was added until a $10 \%$-suspension of red blood cells was obtained.

Fresh cultures of the different $B$. hyodysenteriae isolates were prepared by harvesting a 4-day old culture plate with a sterile cotton swab and stirring the cotton swab in an anaerobic Brain Heart Infusion (BHI) broth (Bio-Rad), supplemented with $10 \%$ of Fetal Bovine Serum (FBS) (Thermo Fisher Scientific). These cultures were incubated for $24 \mathrm{~h}$ under anaerobic conditions at $37{ }^{\circ} \mathrm{C}$ on a rocking platform and for each strain three cultures were made. After incubation, cultures were microscopically examined for purity and the Optical Density at $620 \mathrm{~nm}$ $\left(\mathrm{OD}_{620}\right)$ was measured. Cultures were only retained if their $\mathrm{OD}_{620}$ measured between 0.30 and 0.35. Supernatant was collected by centrifugation at $500 \mathrm{~g}$ for $20 \mathrm{~min}$ and was sterilized by filtration (Millipore, $0.2 \mu \mathrm{m}$ ). The strongly hemolytic strain B204 (ATCC 31212) served as a reference strain in the in vitro hemolysis assay.

The hemolysis assay was performed in 96-well U-bottom microtiter plates. After pipetting $100 \mu \mathrm{L}$ of the $10 \%$ red blood cell suspension in each well, $100 \mu \mathrm{L}$ of the filtered $B$. hyodysenteriae culture supernatant was added. Triton-X $2 \%$ served as a positive control (complete hemolysis) and DGV served as a negative control (no hemolysis). Plates were incubated for two hours at $37^{\circ} \mathrm{C}$ in a $5 \% \mathrm{CO}_{2}$ atmosphere after which the 96-well plate was centrifuged for $10 \mathrm{~min}$ at $500 \mathrm{~g}$. The supernatant of the incubated fluid was transferred to a 96-well IWAKIplate and the absorption at $450 \mathrm{~nm}$ was determined using an ELISA-reader. All assays were performed in triplicate and repeated three times.

\section{Sequencing of hemolysis associated genes}

Complete sequences of the $h l y A, \operatorname{tly} A, \operatorname{tly} B, t l y C$, hemolysin III (BHWA1_RS02195), hemolysin activation protein (BHWA1_RS02885), and hemolysin III channel protein (BHWA1_RS09085) genes were determined for all B. hyodysenteriae strains. For $h l y A$, the ACP1-Fo and ACP1-Re primers were used as described by Barth et al. [26]. For $\operatorname{tly} A$, the primers were designed based on the sequences of tly (GenBank: X61684.1) (tlyA was originally named tly as it was presumed to be the only hemolysin of
Brachyspira) as deposited by Muir et al. [16] and the whole genome sequence of $B$. hyodysenteriae WA1 (GenBank: NC_012225.1) [24]. The tlyB and tly $C$ primers were based on the sequences (GenBank: X73140.1) (tlyB), (GenBank: X73141.1) (tlyC) [17] and their alignment with the whole genome sequence of WA1 respectively. Primers for hemolysin III, hemolysin activation protein and hemolysin III channel protein genes were designed based on the whole genome sequence of B. hyodysenteriae strain WA1 (GenBank: NC_012225.1) [26]. Primers, position as given in the whole genome sequence of WA1 (GenBank: NC_012225.1), product length and annealing temperature are shown in Table 2.

PCR was performed under standard conditions in a $25 \mu \mathrm{L}$ reaction volume with Taq polymerase (Bioline, Taunton, USA). The PCR program started with $95{ }^{\circ} \mathrm{C}$ for $15 \mathrm{~min}$, followed by 35 cycles of $95{ }^{\circ} \mathrm{C}$ for $30 \mathrm{~s}, 1 \mathrm{~min}$ at the primer specific annealing temperature and $72{ }^{\circ} \mathrm{C}$ for $1 \mathrm{~min}$. The final extension step was $72{ }^{\circ} \mathrm{C}$ for $2 \mathrm{~min}$ after which samples were cooled to $4{ }^{\circ} \mathrm{C}$. Optimal annealing temperatures are given for each primer pair in Table 2. For all strains, the sequences were compared to each other and to the whole genome sequence of B. hyodysenteriae strain WA1 [26]. Furthermore, all sequences were compared to the whole genome sequences of 18 additional B. hyodysenteriae strains, including type strain B78 and reference strains B204 and FM88.90. These whole genome sequences were recently described by Black et al. [47].

\section{Statistical analysis}

The in vitro hemolysis test results were analyzed by a one-way ANOVA, with Bonferroni corrections. A P value of $<0.05$ was considered significant and all statistical analysis was performed with the SPSS Statistics 22.0 software (SPSS Inc., Chicago, USA).

\section{Results \\ Phenotypic and molecular identification of $B$. hyodysenteriae isolates}

A collection of $35 \mathrm{~B}$. hyodysenteriae, $15 \mathrm{~B}$. intermedia, 7 B. pilosicoli, 12 B. murdochii, $10 \mathrm{~B}$. innocens isolates, and $1 \mathrm{~B}$. hampsonii isolate has been assembled. During the characterization of the strain collection it was noted that one isolate, M2, that was donated by a diagnostic laboratory, showed only moderate hemolysis on TSA plates supplemented with $5 \%$ sheep blood, although it had been presented as a $B$. hyodysenteriae isolate. Another isolate, D28, had been presented as B. murdochii by a diagnostic laboratory. This isolate was phenotypically identifiable as B. murdochii, but was positive in all B. hyodysenteriae specific PCR's and negative in all species-specific PCR's for other Brachyspira sp.. 
Table 2 Primers, position, product size and annealing conditions for detection of hemolysis related genes tlyA, tlyB, tlyC, hemolysin III, hemolysin activation protein and hemolysin III channel protein

\begin{tabular}{|c|c|c|c|c|}
\hline Target gene: primer names & Nucleotide sequence $\left(5^{\prime} \rightarrow 3^{\prime}\right)$ & Position (NC_012225.1) & Product size (bp) & Temperature annealing $\left({ }^{\circ} \mathrm{C}\right)$ \\
\hline \multicolumn{5}{|l|}{ tlyA: hemolysin A } \\
\hline tlyAS1Fo & GGTATTGGAGATGAATATAC & $267034-267054$ & 956 & 58 \\
\hline tlyAS1Re & TGATGTAGAAGGCTTCTATA & $267969-267989$ & & \\
\hline \multicolumn{5}{|l|}{ tlyB: hemolysin B } \\
\hline tlyBS3Fo & GGAGTGGAGAGAAAGTATTA & $1414613-1414633$ & 974 & 57 \\
\hline tlyBS3Re & TGCTGTAAGCAGACTTATAG & $1415566-1415586$ & & \\
\hline tlyBS4Fo & AGCTGTCCTTCTTCAAGTAC & $1415413-1415433$ & 390 & 63 \\
\hline tlyBS4Re & AGTCGTAGGACAGAAAGAAG & $1415782-1415802$ & & \\
\hline tlyBS2Fo & СССТСТTCATAACCAACATA & $1415533-1415553$ & 1062 & 65 \\
\hline tlyBS2Re & AGGGACTTGCTGAAAAGATA & $1416653-1416673$ & & \\
\hline tlyBS1Fo & TTGTACCAGCAACAACTGAA & $1416575-1416595$ & 1082 & 54 \\
\hline tlyBS1Re & AGCTCTATCTACAGCAATAC & $1417635-1417655$ & & \\
\hline \multicolumn{5}{|l|}{ tlyC: hemolysin C } \\
\hline tlyCFo & TTACGAATGCCTGCTATTTG & $1644915-1644935$ & 1131 & 50 \\
\hline tlyCRe & CTATTTTTAGGCGAGGCTTT & $1646025-1646045$ & & \\
\hline \multicolumn{5}{|l|}{ BHWA1_RS02195: hemolysin III } \\
\hline HlysCBSFo & GGAAAAAGGGATCCTGGAAC & $704725-704745$ & 1570 & 54 \\
\hline HlysCBSRe & TCCTGCTTGTTATCAGCACA & $706278-706298$ & & \\
\hline \multicolumn{5}{|c|}{ BHWA1_RS02885: hemolysin activation protein } \\
\hline Hlys3-1Fo & CTATTGGAGAGCGTACATCT & $503577-503597$ & 1014 & 58 \\
\hline Hlys3-1Re & TACCCTGTACCTACAGAACA & $504571-504591$ & & \\
\hline \multicolumn{5}{|c|}{ BHWA1_RS09085: hemolysin III channel protein } \\
\hline Hlys3-2Fo & CTCCTCCCGTTCAATATGTA & $2156200-2156220$ & 974 & 58 \\
\hline Hlys3-2Re & AATCCGCCATGTAAAACTGC & $2157154-2157174$ & & \\
\hline
\end{tabular}

For the final selection of ten isolates, results of the phenotypic characterization are shown in Table 1. Most isolates showed strong hemolysis after growth for four days on TSA plates supplemented with $5 \%$ sheep blood. However, as mentioned previously, isolate M2 showed only moderate hemolysis and isolate D28 showed weak hemolysis. Eight out of ten isolates were indole positive and two were negative.

The ten selected strains tested positive in the B. hyodysenteriae specific PCRs based on 23S rRNA, nox and tlyA genes. Sequences of the nox genes of all the isolates showed $100 \%$ similarity to previously described B. hyodysenteriae strains retrieved from GenBank. For the ten selected strains the nox gene sequences were identical, except for strain 25cI. The $16 \mathrm{~S}$ rRNA gene sequence of these strains also showed $100 \%$ similarity to previously described B. hyodysenteriae strains retrieved from GenBank. All sequences were deposited in GenBank, accession numbers and sequence length are given in Table 1.

MLST results are given in Table 1 . All 7 genes could be amplified and sequenced for the described isolates. The MLST profiles of isolates 8dII, M1 and M2 are identical and have previously been deposited as sequence type 8 .
All other profiles represent new sequence types but have four or five loci in common with already existing profiles in the pubMLST database. A dendrogram based on the concatenated sequence (4086 bp) of the 7 MLST genes of B. hyodysenteriae and B. intermedia is given in Figure 1 .

\section{In vitro hemolysis of $B$. hyodysenteriae strains shows gradual variation}

Figure 2 displays the in vitro hemolysis of the described $B$. hyodysenteriae strains. The strength of hemolysis showed gradual variation, nevertheless most strains showed a strength of hemolysis in the same range as the B204 reference strain. For strain D28 and M2 the hemolysis was significantly lower than for the B204 reference strain $(P<0.01)$.

\section{Nucleic acid and amino acid substitutions in hemolysis associated genes}

The sequences for hlyA were identical to the whole genome sequences of WA1 and the 18 additional strains [47], except strain 3bIII and 4cI, which differed with regard to two nucleotides. However, these nucleotide differences were synonymous and did not translate into a 


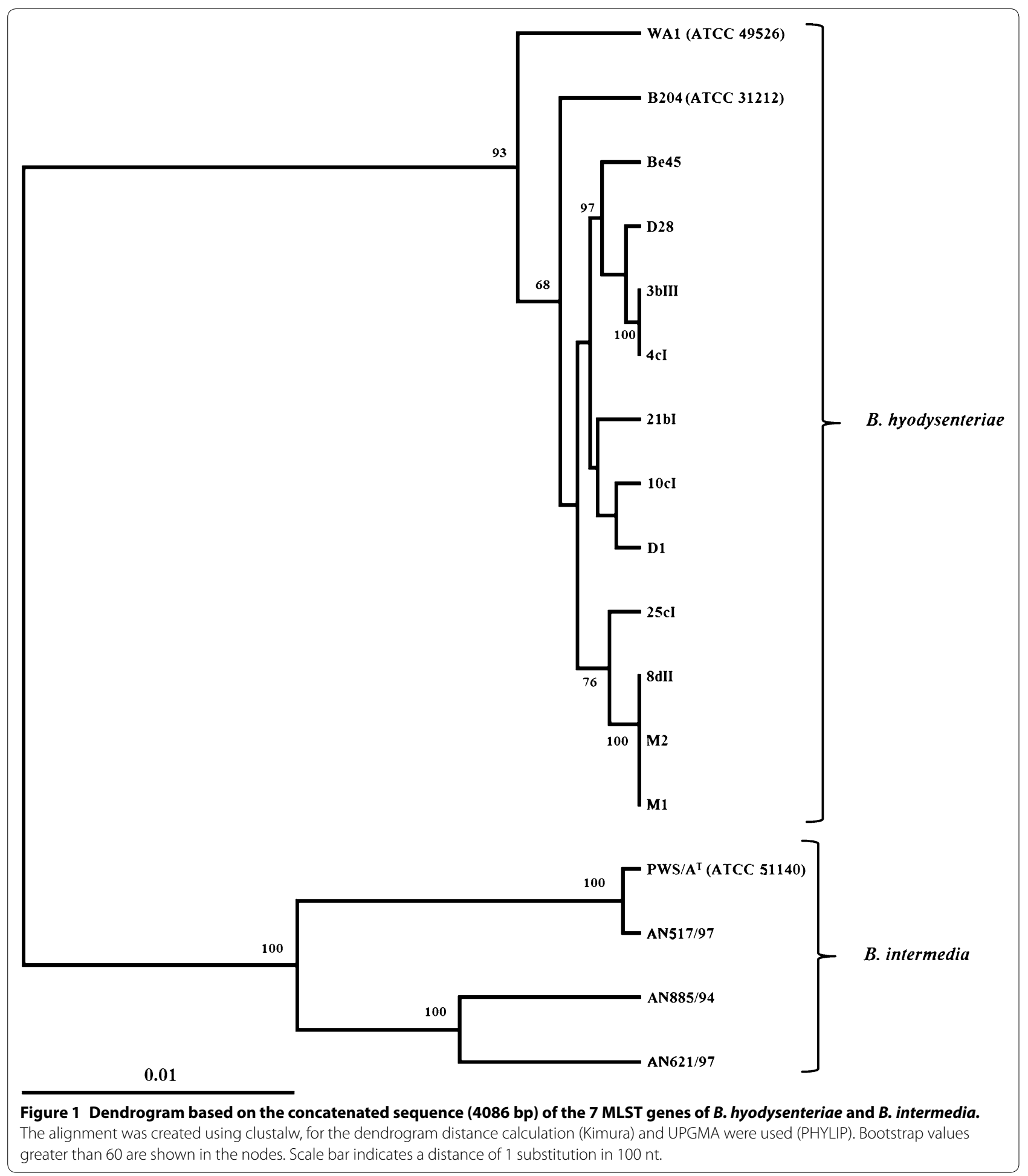

different amino acid sequence. The positive result for all strains in the hlyA-ACP PCR also showed that the hly $A$ gene was placed as expected between the accompanying $f a b$-F and $f a b$-G genes, coding for an ACP-reductase and -synthetase [25].
Weakly hemolytic strain D28 was the only strain with a nucleic acid substitution in the tly $A$ gene. The substitution was located at position $501(\mathrm{G} \rightarrow \mathrm{T})$ as given in Tly (GenBank: X61684.1) by Muir et al. [16] or position 267228 as in the genome sequence of WA1 (GenBank: 


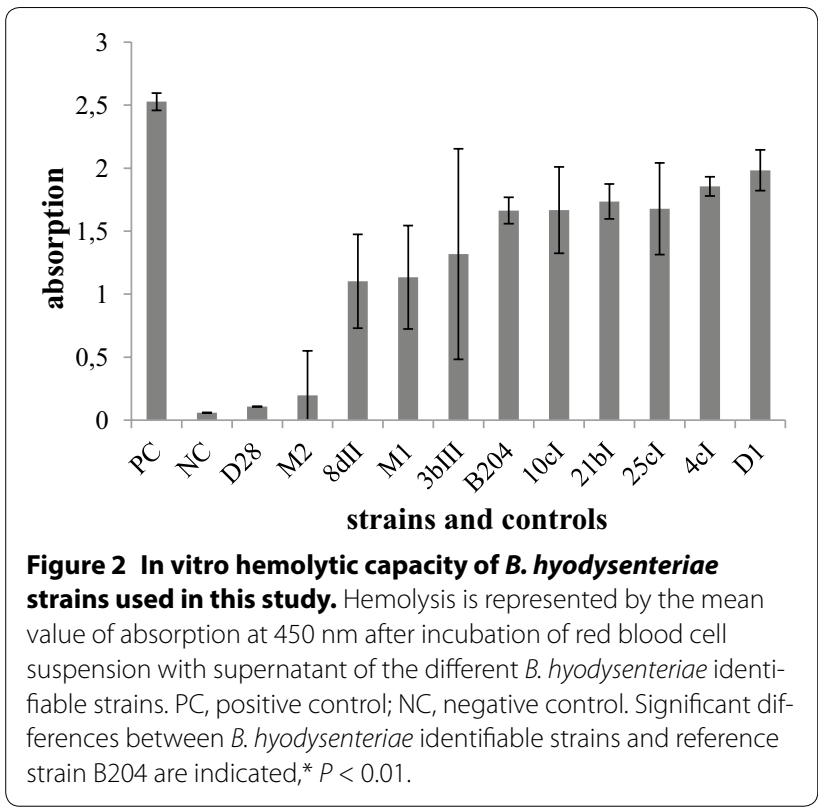

NC_012225.1) [24]. This non-synonymous nucleic acid substitution translated into a different amino acid at position 10 in the amino acid sequence (Glycine $\rightarrow$ Cysteine). In all other whole genome sequences the sequence of tly $A$ was identical to WA1, except for strain ST195 were there was a synonymous substitution in one nucleotide at position $938(\mathrm{~A} \rightarrow \mathrm{C})$ as given in Tly (GenBank: X61684.1) by Muir et al. [16] or position 267725 as in the genome sequence of WA1 (GenBank: NC_012225.1) [24].

The sequence of the $t l y B$ gene showed differences between the isolates and the number of nucleotide changes varied from 1 to 7 as given in Table 3. For all strains, except the weakly hemolytic strain D28, these nucleotide differences were synonymous. The sequence of strain D28 differed at two positions of which the nucleotide change at position $1416206(\mathrm{C} \rightarrow \mathrm{T})$ translates into an amino acid substitution at position 384 in the amino acid sequence (Alanine $\rightarrow$ Threonine). In all other whole genome sequences only one strain (ST195) was reported to have a synonymous substitution [47].

With regard to the $t l y C$ gene, all strains were identical to WA1 and all other whole genome sequences except for weakly hemolytic strain D28 of which the $t l y C$ sequence differed in four nucleotides. Nonetheless this altered nucleotide sequence consisted of synonymous substitutions only.

The hemolysin III gene sequence (BHWA1_RS02195) showed no nucleotide differences for seven of the strains. The strains 8dII, M1 and M2 shared an identical sequence which diverged 10 nucleotides compared to the sequence of $B$. hyodysenteriae reference strain WA1. However, these nucleotide differences did not translate into a different amino acid sequence. The weakly hemolytic strain D28 showed 68 nucleotide differences compared to the sequence of $B$. hyodysenteriae reference strain WA1. These nucleotide differences resulted in 5 amino acid substitutions at following positions: 81 (Valine $\rightarrow$ Isoleucine), 113 (Methionine $\rightarrow$ Valine), 164 (Glutamic acid $\rightarrow$ Aspartic acid), 227 (Threonine $\rightarrow$ Serine), 264 (Valine $\rightarrow$ Isoleucine). The majority of the other whole genome sequences showed a hemolysin III gene sequence identical to WA1, 6 strains showed synonymous nucleotide substitutions and strain B6933 had two amino acid substitutions at position 241 (Methionine $\rightarrow$ Isoleucine) and 335 (Valine $\rightarrow$ Isoleucine).

With regard to the hemolysin activation protein gene (BHWA1_RS02885) all strains showed a difference of 14 or 15 nucleotides with the sequence of $B$. hyodysenteriae reference strain WA1 (Table 3 ). These sequences translated in five amino acid sequence differences

Table 3 Nucleotide and amino acid differences for hemolysis related genes of $B$. hyodysenteriae identifiable strains used in this study

\begin{tabular}{|c|c|c|c|c|c|c|c|c|}
\hline Strain & $\begin{array}{l}\text { In vitro hemo- } \\
\text { lysis }\end{array}$ & tlyA $723 \mathrm{nt}$ & hlyA $237 \mathrm{nt}$ & tlyB $2487 \mathrm{nt}$ & tlyC $807 \mathrm{nt}$ & $\begin{array}{l}\text { Hemolysin III } \\
1335 \mathrm{nt}\end{array}$ & $\begin{array}{l}\text { Hemolysin activa- } \\
\text { tion protein } 675 \mathrm{nt}\end{array}$ & $\begin{array}{l}\text { Hemolysin III chan- } \\
\text { nel protein } 672 \mathrm{nt}\end{array}$ \\
\hline 3blll & ++ & 0 & $2(0)$ & $7(0)$ & 0 & 0 & $15(5)$ & $2(1)$ \\
\hline $4 \mathrm{Cl}$ & ++ & 0 & $2(0)$ & $7(0)$ & 0 & 0 & $15(5)$ & $2(1)$ \\
\hline $8 d \|$ & ++ & 0 & 0 & 0 & 0 & $10(0)$ & $15(5)$ & $0(0)$ \\
\hline $10 \mathrm{cl}$ & ++ & 0 & 0 & $5(0)$ & 0 & 0 & $14(5)$ & $1(0)$ \\
\hline $21 \mathrm{bl}$ & ++ & 0 & 0 & $1(0)$ & 0 & 0 & $15(5)$ & $1(0)$ \\
\hline $25 \mathrm{cl}$ & ++ & 0 & 0 & $7(0)$ & 0 & 0 & $14(5)$ & $1(0)$ \\
\hline D1 & ++ & 0 & 0 & $5(0)$ & 0 & 0 & $14(5)$ & $1(0)$ \\
\hline D28 & \pm & $1(1)$ & 0 & $2(1)$ & $4(0)$ & $63(5)$ & $44(8)$ & $12(1)$ \\
\hline M1 & ++ & 0 & 0 & 0 & 0 & $10(0)$ & $15(5)$ & $0(0)$ \\
\hline M2 & + & 0 & 0 & 0 & 0 & $10(0)$ & $15(5)$ & $0(0)$ \\
\hline
\end{tabular}

Differences compared with the genome sequence of $B$. hyodysenteriae strain WA1. Number of amino acid changes are given in brackets. 
at following positions: 51 (Proline $\rightarrow$ Serine), 56 (Valine $\rightarrow$ Isoleucine), 59 (Valine $\rightarrow$ Leucine), 82 (Leucine $\rightarrow$ Isoleucine), 93 (Valine $\rightarrow$ Isoleucine). Strain D28 showed 41 nucleotide differences compared to the sequence of $B$. hyodysenteriae reference strain WA1 (Table 3), which translates into an amino acid sequence different from that of strain WA1 by 8 amino acids: 47 (Threonine $\rightarrow$ Isoleucine), 49 (Valine $\rightarrow$ Methionine), 56 (Valine $\rightarrow$ Isoleucine), 79 (Valine $\rightarrow$ Isoleucine), 82 (Leucine $\rightarrow$ Isoleucine), 111 (Valine $\rightarrow$ Isoleucine), 114 (Leucine $\rightarrow$ Proline), 133 (Methionine $\rightarrow$ Isoleucine). The whole genome sequences of the 18 additional B. hyodysenteriae strains showed various amino acid substitutions compared to WA1. Six strains shared the five amino substitutions as seen in most of the strains of this study, strains B204, B6933 and B78 showed one additional amino acid substitution at position 157 (Lysine $\rightarrow$ Glutamic acid). One strain (NSW15) showed three amino acid substitutions compared to WA1 at positions 19 (Lysine $\rightarrow$ Arginine), 133 (Methionine $\rightarrow$ Isoleucine), 180 (Isoleucine $\rightarrow$ Methionine), and strains Q17, B8044 and 865 showed four amino acid substitutions compared to WA1 at positions 54 (Isoleucine $\rightarrow$ Methionine), 82 (Leucine $\rightarrow$ Isoleucine), 93 (Valine $\rightarrow$ Isoleucine) and 157 (Glutamic acid $\rightarrow$ Lysine).

The sequences for hemolysin III channel protein gene (BHWA1_RS09085) of the strains in this study were either identical to that of $B$. hyodysenteriae reference strain WA1, differed by 1 or 2 nucleotides, or differed by 12 (strain D28). For strains $3 \mathrm{bIII}$ and $4 \mathrm{cI}$ this resulted in an amino acid substitution at position 217 (Arginine $\rightarrow$ Isoleucine), and for strain D28 at position 209 (Valine $\rightarrow$ Isoleucine). For the other whole genome sequences seven strains showed an identical hemolysin III channel protein gene sequence to WA1, nine strains shared a synonymous nucleotide substitution at position 2156792 as given in the genome sequence of WA1. Strain B78 showed one amino acid substitution at position 120 (Alanine $\rightarrow$ Threonine).

Table 3 displays the number of nucleotide and amino acid differences for the sequences of the hly $A$, tly $A$, tlyB, tlyC, hemolysin III, hemolysin activation protein and hemolysin III channel protein genes between the $B$. hyodysenteriae strains in comparison with the genome sequence of $B$. hyodysenteriae reference strain WA1. All sequences have been deposited in GenBank (accession numbers KM112034-KM112073, KU215622-KU215658).

\section{Discussion}

This study describes quantification of hemolytic capacity of $B$. hyodysenteriae strains, and provides evidence that the degree of hemolysis can vary within the species $B$. hyodysenteriae. The phenotypic characterization tests, species-specific PCR, and sequences of the nox and $16 \mathrm{~S}$ rRNA genes of moderately or weakly hemolytic strains show that these strains belong to the species $B$. hyodysenteriae. The dendrogram based on the MLST results (Figure 1) shows that the weakly hemolytic $B$. hyodysenteriae strains are nested within clades containing strongly hemolytic $B$. hyodysenteriae strains. Even if only DNA/DNA hybridization might be considered sufficiently accurate enough to effectively identify a strain, the strains described here would undoubtedly be identified as B. hyodysenteriae in all currently used methods for genetic identification (PCR, nox and 16S rRNA sequencing, MLST).

The comparative sequence analysis of the hemolysis associated genes leads to a hypothesis with regard to the underlying mechanism of the weak hemolysis. The weakly hemolytic $B$. hyodysenteriae strain D28 possesses nucleotide sequence differences in the tlyA, tlyB, hemolysin III, hemolysin activation protein and hemolysin III channel protein genes resulting in amino acid substitutions. These sequences differ from those of all other strains in the study and from that of reference strain WA1. Whether the amino acid substitutions reported here are the sole reason for the weak hemolysis of this strain needs further studies. In our opinion the most important genes involved in the strong hemolytic phenotype of $B$. hyodysenteriae are tly $A$, hly $A$ and probably hemolysin III. Deletion mutants for tlyA have been reported to be weakly hemolytic on blood containing agar plate [23]. The role of ACP in acylation of toxins has been demonstrated for other toxins, such as RTX toxins [24], which makes it likely that hlyA encoding an ACP plays a role in the hemolytic capacity of $B$. hyodysenteriae. Hemolysin III harbors a conservative domain yqfA, a predicted channel-forming protein of the hemolsyin III family, which might indicate its role in B. hyodysenteriae hemolysis. Whether this reduced hemolytic capacity can be attributed to one of the amino acid changes in one of the hemolysis associated genes, remains to be determined. In order to completely elucidate this, the construction of specific mutants of B. hyodysenteriae which harbor one of the divergent hemolysis associated genes is a prerequisite. This might be hampered by the fact that is difficult to genetically manipulate $B$. hyodysenteriae.

Not only a difference in amino acid sequence, which can affect the function of a protein, might influence the gradation in hemolytic capacity but there might also occur a more distant variance such as altered activity of promoter regions or altered transcription of genes under specific circumstances in vitro as well as in vivo. Although repeated subculturing can result in phenotypical changes such as loss of hemolysis [48], this has, to our knowledge, not been described for B. hyodysenteriae. 
Besides, already during primary isolation of strains D28 and M2, hemolysis was always weak and moderate, respectively.

Brachyspira hyodysenteriae strain M2 is only moderately hemolytic. However, the nucleotide sequence differences observed for strain M2 did not result in amino acid changes except for the hemolysin activation protein gene. However, for this gene amino acid substitutions were observed for all investigated strains compared to WA1. It should be mentioned that unlike D28, which originated from a farm where only mild diarrhea was present, M2 originated from a farm where pigs were suffering from mucohemorrhagic diarrhea. Alongside M2, another isolate M1, originated from the same farm. The presence of different strains with divergent biological properties on one farm could influence the outcome of control measurements, since these strains may differ in other biological properties as well, such as their antimicrobial resistance.

Strain D28 originated from a farm were only mild diarrhea was present. In preliminary trials, in which pigs were inoculated with this strain, no symptoms of SD were observed, even if the strain was shed in the feces of the inoculated pigs at $10^{7}$ copies/g feces. Even though the significance of the presence of weakly hemolytic strains of $B$. hyodysenteriae in a herd as a hazard for porcine health is not clear at the moment, the mere occurrence of weakly hemolytic strains of B. hyodysenteriae poses problems for the diagnosis of swine dysentery. When diagnosis is primarily based on microbial culture procedures, these strains could be mistaken for $B$. intermedia or B.murdochii, since the phenotypic profile of weakly haemolytic, indole positive $B$. hyodysenteriae is equal to that of $B$. intermedia and the phenotypic profile of weakly haemolytic, indole negative $B$. hyodysenteriae is equal to that of $B$. murdochii. When diagnosis is primarily based on the current PCR tests, the degree of hemolysis of the specific strain cannot be estimated. If a herd tests positive for B. hyodysenteriae, this may influence the trading possibilities of the farm in question, because of the possible risk of $B$. hyodysenteriae carrier animals. In order to avoid misdiagnosis, the combination of phenotypic characterization and PCR, complemented with sequencing if necessary, is presumably the most complete method for species identification of Brachyspira sp. for now.

Although in our collection of 35 isolates, spanning a time-period of 2 years, only two B. hyodysenteriae strains were found with an aberrant hemolytic phenotype, appearance of weakly hemolytic, possibly low virulent strains of $B$. hyodysenteriae may affect herd dysentery status, with great impact on a farms trading opportunities. The prevalence of weakly hemolytic B. hyodysenteriae could be underestimated since it has not been regularly looked for or could go unnoticed if PCR and microbial culture are not combined.

\section{Competing interests}

The authors declare that they have no competing interests.

\section{Authors' contributions}

MM participated in the design of the study, performed the experiments, analyzed the data and drafted the manuscript. NDP, LVM and MV participated in the experiments. FB participated in the design of the study and edited the manuscript. RD helped to interpret the results and edited the manuscript. FP, $\mathrm{AM}$ and $\mathrm{FH}$ coordinated the study, participated in the design of the study, helped to interpret the results and edited the manuscript. All authors read and approved the final manuscript.

\section{Acknowledgements}

This work was supported by the Flemish Agency for Innovation by Science and Technology (IWT), Grant Nr. IWT Landbouw 100850 and the Industrial Research Fund (IOF) Grant Nr F2014/IOF-ConcepTT/272. The participation of several swine veterinarians and diagnostic laboratories in this study is greatly appreciated.

\section{Author details}

${ }^{1}$ Department of Pathology, Bacteriology and Avian Diseases, Faculty of Veterinary Medicine, Ghent University, Salisburylaan 133, B-9820 Merelbeke, Belgium. ${ }^{2}$ Technology and Food Science Unit, Institute for Agricultural and Fisheries Research (ILVO), Brusselsesteenweg 370, B-9090 Melle, Belgium.

Received: 12 April 2016 Accepted: 5 June 2016

Published online: 23 June 2016

\section{References}

1. Alvarez-Ordóñez A, Martínez-Lobo FJ, Arguello H, Carvajal A, Rubio P (2013) Swine dysentery: aetiology, pathogenicity, determinants of transmission and the fight against the disease. Int J Environ Res Publ Health 10:1927-1947

2. Råsbäck T, Fellström C, Bergsjø B, Cizek A, Collin K, Gunnarsson A, Jensen SM, Thomson J, Vyt P, Pringle M (2005) Assessment of diagnostics and antimicrobial susceptibility testing of Brachyspira species using a ring test. Vet Microbiol 109:229-243

3. Ter Huurne AA, Gaastra W (1995) Swine dysentery: more unknown than known. Vet Microbiol 46:347-360

4. Knoop FC (1981) Investigation of a hemolysin produced by enteropathogenic investigation of a hemolysin produced by enteropathogenic Treponema hyodysenteriae. Infect Immun 31:193-198

5. Kent KA, Lemcke RM, Lysons RJ (1988) Production, purification and molecular weight determination of the haemolysin of Treponema hyodysenteriae. J Med Microbiol 27:215-224

6. Jensen TK, Christensen AS, Boye M (2010) Brachyspira murdochii colitis in pigs. Vet Pathol 47:334-338

7. Neef N, Lysons RJ, Trott DJ, Hampson DJ, Jones PW, Morgan JH (1994) Pathogenicity of porcine intestinal spirochetes in gnotobiotic pigs. Infect Immun 62:2395-2403

8. Chander Y, Primus A, Oliveira S, Gebhart CJ (2012) Phenotypic and molecular characterization of a novel strongly hemolytic Brachyspira species, provisionally designated "Brachyspira hampsonii". J Vet Diagn Invest 24:903-910

9. Råsbäck T, Jansson DS, Johansson K, Fellström C (2007) A novel enteropathogenic, strongly haemolytic spirochaete isolated from pig and mallard, provisionally designated "Brachyspira suanatina" sp. nov. Environ Microbiol 9:983-991

10. Costa MO, Hill JE, Fernando C, Lemieux HD, Detmer SE, Rubin JE, Harding JC (2014) Confirmation that "Brachyspira hampsonii" clade I (Canadian strain 30599) causes mucohemorrhagic diarrhea and colitis in experimentally infected pigs. BMC Vet Res 10:129

11. Wilberts BL, Arruda PH, Kinyon JM, Madson DM, Frana TS, Burrough ER (2014) Comparison of lesion severity, distribution, and colonic mucin 
expression in pigs with acute swine dysentery following oral inoculation with "Brachyspira hampsonii" or Brachyspira hyodysenteriae. Vet Pathol 51:1096-1108

12. Rubin JE, Costa MO, Hill JE, Kittrell HE, Fernando C, Huang Y, O'Connor B, Harding JC (2013) Reproduction of mucohaemorrhagic diarrhea and colitis indistinguishable from swine dysentery following experimental inoculation with "Brachyspira hampsonii" strain 30446. PLoS One 8:e57146

13. Mushtaq M, Zubair S, Råsbäck T, Bongcam-Rudloff E, Jansson DS (2015) Brachyspira suanatina sp. nov., an enteropathogenic intestinal spirochaete isolated from pigs and mallards: genomic and phenotypic characteristics. BMC Microbiol 15:208

14. Lemcke RM, Burrows MR (1982) Studies on a haemolysin produced by Treponema hyodysenteriae. J Med Microbiol 15:205-214

15. Lysons RJ, Kent K, Bland P, Sellwood R, Robinson WF, Frost J (1991) A cytotoxic haemolysin from Treponema hyodysenteriae--a probable virulence determinant in swine dysentery. J Med Microbiol 34:97-102

16. Muir S, Koopman MB, Libby SJ, Joens L, Heffron F, Kusters JG (1992) Cloning and expression of a Serpula (Treponema) hyodysenteriae hemolysin gene. Infect Immun 60:529-535

17. ter Huurne AA, Muir S, van Houten M, van der Zeijst BA, Gaastra W, Kusters JG (1994) Characterization of three putative Serpulina hyodysenteriae hemolysins. Microb Pathog 16:269-282

18. Hsu T, Hutto DL, Minion FC, Zuerner RL, Wannemuehler MJ (2001) Cloning of a beta-hemolysin gene of Brachyspira (Serpulina) hyodysenteriae and its expression in Escherichia coli. Infect Immun 69:706-711

19. Wren BW, Stabler RA, Das SS, Butcher PD, Mangan JA, Clarke JD, Casali N Parish T, Stoker NG (1998) Characterization of a haemolysin from Mycobacterium tuberculosis with homology to a virulence factor of Serpulina hyodysenteriae. Microbiology 144:1205-1211

20. Rahman A, Srivastava SS, Sneh A, Ahmed N, Krishnasastry MV (2010) Molecular characterization of tlyA gene product, Rv1694 of Mycobacterium tuberculosis: a non-conventional hemolysin and a ribosomal RNA methyl transferase. BMC Biochem 11:35

21. Chu L, Burgum A, Kolodrubetz D, Holt SC (1995) The 46-kilodaltonhemolysin gene from Treponema denticola encodes a novel hemolysin homologous to aminotransferases. Infect Immun 63:4448-4455

22. ter Huurne AA, Muir S, van Houten M, Koopman MB, Kusters JG, van der Zeijst BA, Gaastra W (1993) The role of hemolysin(s) in the pathogenesis of Serpulina hyodysenteriae. Zentralbl Bakteriol 278:316-325

23. Hyatt DR, ter Huurne A, Van Der Zeijst B, Joens L (1994) Reduced virulence of Serpulina hyodysenteriae hemolysin-negative mutants in pigs and their potential to protect pigs against challenge with a virulent strain. Infect Immun 62:2244-2248

24. Bellgard MI, Wanchanthuek P, La T, Ryan K, Moolhuijzen P, Albertyn Z, Shaban B, Motro Y, Dunn DS, Schibeci D, Hunter A, Barrero R, Phillips N, Hampson DJ (2009) Genome sequence of the pathogenic intestinal spirochete brachyspira hyodysenteriae reveals adaptations to its lifestyle in the porcine large intestine. PLoS One 4:e4641

25. Zuerner RL, Stanton TB, Minion FC, Li C, Charon NW, Trott DJ, Hampson DJ (2004) Genetic variation in Brachyspira: chromosomal rearrangements and sequence drift distinguish B. pilosicoli from B. hyodysenteriae. Anaerobe 10:229-237

26. Barth S, Gömmel M, Baljer G, Herbst W (2012) Demonstration of genes encoding virulence and virulence life-style factors in Brachyspira spp. isolates from pigs. Vet Microbiol 155:438-443

27. Ramarao N, Sanchis V (2010) The pore-forming haemolysins of Bacillus cereus: a review. Toxins 5:1119-1139

28. Mahu M., De Pauw N, Vande Maele L, Verlinden M, Boyen F, Ducatelle R, Haesebrouck F, Martel A, Pasmans F (2014) Weakly hemolytic Brachyspira hyodysenteriae strains in pigs. In: Adler B, Frey J (eds) Proceedings of the $3^{\text {rd }}$ prato conference on the pathogenesis of bacterial diseases of animals, Prato, October 2014. The Society, p 39

29. Lysons RJ, Lemcke RM, Bew J, Burrows MR, Alexander TJL (1982) An avirulent strain of Treponema hyodysenteriae isolated from herds free of swine dysentery. In: Necoechea RR, Pijoan, C, Casarín, A, Guzmán M (eds) Proceedings of the $7^{\text {th }}$ international pig veterinary society congress, Mexico City, July 1982. The Society, p 40

30. Hampson DJ, La T, Phillips ND (2015) Emergence of Brachyspira species and strains: reinforcing the need for surveillance. Porcine Health Manag $1: 8$

31. Jenkinson SR, Wingar CR (1981) Selective medium for the isolation of Treponema hyodysenteriae. Vet Rec 109:384-385

32. Fellström C, Gunnarsson A (1995) Phenotypical characterisation of intestinal spirochaetes isolated from pigs. Res Vet Sci 59:1-4

33. Hommez J, Castryck F, Haesebrouck F, Devriese LA (1998) Identification of porcine Serpulina strains in routine diagnostic bacteriology. Vet Microbiol 62:163-169

34. RåsbäckT, Fellström C, Gunnarsson A, Aspán A (2006) Comparison of culture and biochemical tests with PCR for detection of Brachyspira hyodysenteriae and Brachyspira pilosicoli. J Microbiol Meth 66:347-353

35. Leser TD, Møller K, Jensen TK, Jorsal SE (1997) Specific detection of Serpulina hyodysenteriae and potentially pathogenic weakly beta-haemolytic porcine intestinal spirochetes by polymerase chain reaction targeting $23 \mathrm{~S}$ rDNA. Mol Cell Probe 11:363-372

36. La T, Phillips ND, Hampson DJ (2003) Development of a duplex PCR assay for detection of Brachyspira hyodysenteriae and Brachyspira pilosicoli in pig feces. J Clin Microbiol 41:3372-3375

37. Phillips ND, La T, Amin MM, Hampson DJ (2010) Brachyspira intermedia strain diversity and relationships to the other indole-positive Brachyspira species. Vet Microbiol 143:246-254

38. Atyeo RF, Stanton TB, Jensen NS, Suriyaarachichi DS, Hampson DJ (1999) Differentiation of Serpulina species by NADH oxidase gene (nox) sequence comparisons and nox-based polymerase chain reaction tests. Vet Microbiol 67:47-60

39. Weissenböck H, Maderner A, Herzog AM, Lussy H, Nowotny N (2005) Amplification and sequencing of Brachyspira spp. specific portions of nox using paraffin-embedded tissue samples from clinical colitis in Austrian pigs shows frequent solitary presence of Brachyspira murdochii. Vet Microbiol 111:67-75

40. Johansson K, Duhamel GE, Bergsjö B, Engvall EO, Persson M, Pettersson $B$, Fellström C (2004) Identification of three clusters of canine intestinal spirochaetes by biochemical and 165 rDNA sequence analysis. J Med Microbiol 53:345-350

41. Basic Local Alignment Search Tool. https://blast.ncbi.nlm.nih.gov Accessed 4 Jan 2016

42. Råsbäck T, Johansson KE, Jansson DS, Fellström C, Alikhani MY, La T, Dunn DS, Hampson DJ (2007) Development of a multilocus sequence typing scheme for intestinal spirochaetes within the genus Brachyspira. Vet Microbiol 153:4074-4087

43. Verlinden M, Pasmans F, Garmyn A, De Zutter L, Haesebrouck F, Martel A (2012) Occurrence of viable Brachyspira spp. on carcasses of spent laying hens from supermarkets. Food Microbiol 32:321-324

44. Brachyspira MLST Databases. www.pubmlst.org/brachyspira. Accessed 21 Apr 2016

45. Osorio J, Carvajal A, Naharro G, La T, Phillips ND, Rubio P, Hampson DJ (2012) Dissemination of clonal groups of Brachyspira hyodysenteriae amongst pig farms in Spain, and their relationships to isolates from other countries. PLoS One 7:e39082

46. Fedorka-Cray PJ, Huether MJ, Stine DL, Anderson GA (1990) Efficacy of a cell extract from Actinobacillus (Haemophilus) pleuropneumoniae serotype 1 against disease in swine. Infect Immun 58:358-365

47. Black M, Moolhuijzen P, Barrero R, La T, Phillips N, Hampson D, Herbst W, Barth S, Bellgard M (2015) Analysis of multiple Brachyspira hyodysenteriae genomes confirms that the species is relatively conserved but has potentially important strain variation. PLoS One 10:e0131050

48. Peppler MS (1982) Isolation and characterization of isogenic pairs of domed hemolytic and flat nonhemolytic colony types of Bordetella pertussis. Infect Immun 35:840-851 